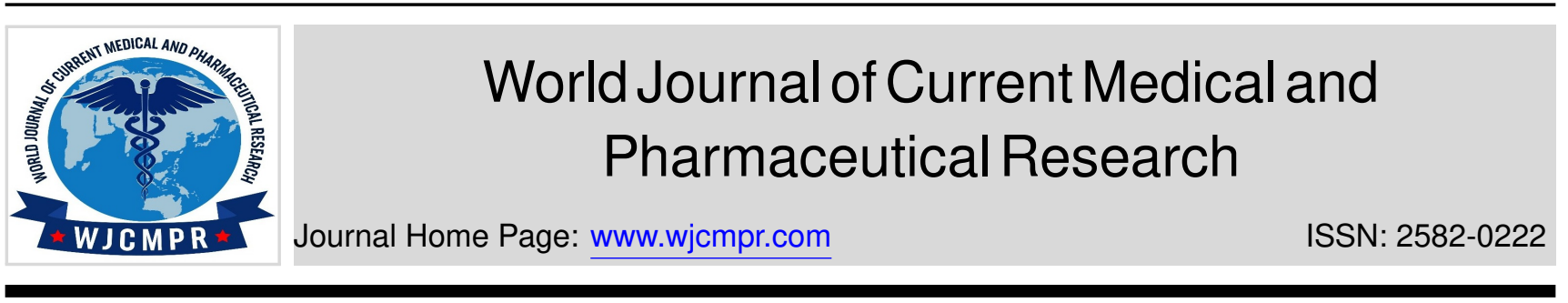

\title{
Formulation and evaluation of orally disintegrating tablet of metoclopramide hydrochloride
}

\author{
Sujan Dawadi ${ }^{1}$, Bipindra Pandey ${ }^{1,2, *}$, Sabina Nepal ${ }^{1}$, Yamuna Gurau ${ }^{1}$, Rashmi Shahi ${ }^{1}$, Bijay Gautam ${ }^{1,2}$, \\ Deepak Akauliya $^{1}$, Manoj Pandit ${ }^{3}$, Sailendra Chaudhary ${ }^{4}$, Chandrika Adhikari Mahat. ${ }^{4}$ \\ 1. Scholar, Bachelor of Pharmacy, Asian College for Advance Studies, Purbanchal Universsity, Lalitpur, Nepal \\ 2. Research Scholar, Master of Pharmaceutical Sciences, School of Health and Allied Sciences, Pokhara University, Kaski, Nepal \\ 3. Lecturer, Department of Pharmacology, Universal College of Medical Sciences, Tribhuvan University, Bhairahawa, Nepal \\ 4. Lecturer, Department of Pharmacy, Asian College for Advance Studies, Purbanchal University, Lalitpur, Nepal
}

\section{ARTICLE INFO}

\section{Article history:}

Received 18.10.2020

Accepted 05.12.2020

Published 15.12.2020

* Corresponding Author:

Bipindra Pandey

bipindra.p101@gmail.com

https://doi.org/

10.37022/wjcmpr.vi.162

Produced By

South Asian Academic

Publications

\begin{abstract}
A B S T R A C T
Orally disintegrating drug delivery is currently the gold standard in the pharmaceutical industry where it is regarded as the fastest, safest, convenient, and most economic method of drug delivery having the highest patient compliance and preferred over conventional tablets. The goal of this study was to formulate and evaluate oral disintegrating tablets (ODTs) of Metoclopramide hydrochloride to overcome swallowing difficulties. The key to developing successful ODT formulation by direct compression method is to select the right super disintegrant. Nine formulations were prepared using different super disintegrants such as sodium starch glycolate (SSG), croscarmellose sodium (CCS), and crospovidone (CP) at three concentrations i.e. $2.8 \%, 4 \%$, and $4.8 \%$. The formulation was evaluated for pre and post-compression parameters like angle of repose, compressibility index, Hausner's ratio, uniformity of content, thickness, hardness, friability, drug content, wetting time, water absorption ratio, dispersion time, in-vitro disintegration time etc. Results revealed that among the 9 formulations, the formulation MHF9 containing $4.8 \%$ of crospovidone was selected as the best formulation as its wetting time 28 second, disintegration and dispersion time 7 second and 18 seconds respectively, percentage drug release after 15 minutes was $102.52 \%$.
\end{abstract}

Keywords: Formulation; orally disintegrating tablets; metoclopramide hydrochloride; direct compression; superdisintegrants.

\section{INTRODUCTION}

Recent progress in novel drug delivery system aims to improve the safety and efficacy of the drug molecule by formulating a dosage form being for the administration. A solid dosage form that dissolves or disintegrates rapidly in the oral cavity, resulting in solution or suspension without the need for water is known as orally disintegrating tablets (ODTs). These are newer types of tablets that break up in saliva within a few seconds. Oral disintegration tablets offer some advantages over conventional tablets [1].

Dysphasia is a common problem encountered in all age groups, especially the elderly and pediatrics because of physiological changes associated with those groups. In concerned to oral solid dosage form such problems consequences in a high occurrence of noncompliance and unproductive therapy. Nowadays, increasing consideration have be remunerated to formulate not only rapid disintegrating tablets to facilitate are swallow but also orally decomposed tablets that are intended to disintegrate rapidly in the mouth. ODTs offer an advantage for the population who have difficulty in swallowing conventional tablets or capsules, bedridden, mentally sick, and uncooperative patients suffering from nausea, motion sickness, sudden episodes of allergic attack, or coughing [2]. The major benefits of such dosage form, in terms of patient compliance, rapid onset of action, increased bioavailability, good stability, and good flavor enhance the suitability of bitter tasting drugs that make these tablets popular as a dosage form of choice in the current market [3].

The basic approach used in the development of an oral disintegration tablet is the use of super disintegrants. Due to 
the presence of super disintegrants, it gets dissolved quickly, resulting in rapid absorption of drugs which in turn provides rapid onset of action. Since absorption takes place directly from the mouth and avoids the first-pass metabolism, so bioavailability of the drug increases. There are various natural disintegrants like gum karaya, modified starch, agar, and synthetic disintegrants like microcrystalline cellulose, crospovidone, croscarmellose sodium, sodium starch glycolate, etc. which have been used in the formulation of fast dissolving tablets at concentration range up to $10 \%$ by weight relative to the total weight of dosage form [4].

In the modern history, numerous techniques cover for the development of orodispersible tablets such as freeze drying or lyophilization, spray drying, molding, sublimation, mass extrusion, and direct compression [5]. Due to low manufacturing costs, conventional pieces of equipment, and a few number of processing steps lead this direct compression technique to be a preferable way to manufacturing orodispersible tablets [4].

Metoclopramide hydrochloride is a free water-soluble clinically potent antiemetic and gastro-prokinetic drug effective for the prevention of different types of emesis. Its conventional dosage form such as tablet and solution give poor bioavailability due to extensive first-pass metabolism [6,7]. In addition to its bitter taste, difficulty swallowing tablets or nausea/vomiting may reduce patient adherence to therapy. The newly developed formulations should try to diminish the patient noncompliance and improve palatability.

In the present study, we attempted to formulate and evaluation of an orodispersible tablet of Metoclopramide $\mathrm{HCl}$ that was manufactured through a direct compression technique using cross carmellose sodium, sodium starch glycolate, and crospovidone as super disintegrants. The study aimed to assess the effect of the super disintegrants on wetting time, dispersion time, and disintegration time profile of the orodispersible tablets.

\section{MATERIALS AND METHODS}

The study was carried out in the year 2017 at the Pharmaceutics laboratory at Asian College for Advance Studies (ACAS), Lalitpur, Nepal.

\section{Materials}

Metoclopramide hydrochloride (an active pharmaceutical ingredient) and super disintegrant agents such as cross carmellose sodium (CCS), sodium starch glycolate (SSG), and cross povidone (CP) was obtained from Chemi Drug Industries Pvt. Ltd. Kathmandu, Nepal. Each super disintegrant was tested at $2.8 \%, 4 \%$, and $4.8 \%$ concentrations using the maximum concentration as mentioned in the Handbook of pharmaceutical excipients. Mannitol and microcrystalline cellulose PH 102 were used as a binding and filling agent. The vanilla and sodium saccharin was use as a flavoring and sweetening agent. Talc and aerosol were used as lubricant and magnesium stearate as a glidant. All the excipients used in this research were pharmaceutical grade.

\section{Methods}

\section{Drug-Excipient Compatibility Study}

In this study, each of $50 \mathrm{mg}$ of active pharmaceutical ingredient (i.e. Metoclopramide HCL) and the other formulation excipients were mixed in 1:1 ratio in different vials. 10 excipients were taken in different vials and active drug was added in each. All these experiments were performed three sets. Then, above vials were stored as follows for checking drug-excipients interactions.

1. Normal room temperature conditions, i e $25^{\circ} \mathrm{C}$ and $60 \%$ relative humidity, plugged.

2. Accelerated temperature conditions, i.e. $40^{\circ} \mathrm{C}$ and $75 \%$ relative humidity, both plugged and unplugged conditions.

For maintaining this above condition, humidity chamber was used [8]. It was checked for physical compatibility (state, color, and odor) in interval of 7 days for a month.

\section{Preparation of orally disintegrating tablets}

Orally disintegrating tablets of Metoclopramide HCL were manufactured through the direct compression technique. A batch of 150 tablets was prepared for all the designed nine formulations and detail of the components of the formulation as mentioned in Table 1. All the excipients and active pharmaceutical ingredients with proper quantities were sieved through mesh \# 80 separately. Firstly, Metoclopramide hydrochloride and super disintegrants were mixed properly. Mannitol and microcrystalline cellulose PH 102 were mixed separately followed by sodium saccharin and vanilla flavor. After that aerosol, magnesium stearate and talc were mixed. At last, the mixed powder was blended in the polythene bag. Finally, the resultant final blend was directly compressed into tablets using 12 station rotary press machines with a $10 \mathrm{~mm}$ diameter flat round shape punch. Before tablet preparation, the entire powder blends were evaluated for the following pre-formulation parameters [9, 10].

\section{Evaluation of pre-formulation parameter The angle of repose $(\theta)$}

. The angle of repose $(\theta)$ was determined according to the free standing cone funnel method. The accurately weighed granules or blend was allowed to flow through the funnel freely onto the graph paper, until its apex and the funnel tip touches each other, till a highest heap height $(\mathrm{h})$ was obtain. The radius ( $r$ ), of the granule or powder heap, was calculated and the angle of repose was computed using the following equation:

$$
\theta=\tan ^{-1}(\mathrm{~h} / \mathrm{r})
$$




\section{Bulk density $(\delta \mathbf{b})$.}

Powder bulk density $(\delta \mathrm{b})$ was measured via placing pre sieved drug excipients blend into a graduated cylinder and initial volume of granules $\left(\mathrm{V}_{0}\right)$ and weight of the granules (W) were taken "as it is".

$$
\text { Bulk density }=W / V_{0}
$$

\section{Tapped density.}

The measuring cylinder containing a known mass of blend was tapped for a fixed time using a tap density tester. The final volume $\left(\mathrm{V}_{f}\right)$ occupied in the cylinder and the weight $(\mathrm{W})$ of the blend was measured. The tapped density was calculated using the following formula.

$$
\text { Tapped density }=\mathrm{W} / \mathrm{V}_{\mathrm{f}}
$$

\section{Compressibility index (CI) .}

The simplest way of measurement of free flow property of powder was compressibility, an indication of the ease with which a material can be induced to flow was given by $\%$ compressibility which was calculated as follows:

$$
\mathrm{Cl}=\mathrm{V}_{0}-\mathrm{V}_{\mathrm{f}} / \mathrm{V}_{0} * 100
$$

\section{Hausner's ratio.}

It indicates the flow properties of the granules and was measured by the ratio of tapped density to the bulk density.

$$
\text { Hausner's ratio }=\text { Tapped density } / \text { Bulk density }
$$

\section{Evaluation parameter of formulated tablets}

All the formulated tablets were undertaken for the following parameters.

\section{Physical appearance.}

The physical appearance of a tablet such as size, shape, color, odor, taste, surface texture, physical flaws, visual identity, and overall "elegance" were necessary for consumer acceptance and legibility of any identifying marking.

\section{Dimensional analysis.}

The thickness and tablets diameter were determined using Vernier caliper. The measurement was carried out in triplicate and average values were calculated.

\section{Breaking force or Hardness.}

The resistance of the tablet to chipping, abrasion, or breakage under the condition of storage transformation and handling before usage depends on its hardness. The breaking force of the tablet of each formulation was determined using Monsanto hardness tester and expressed as tensile strength $\left(\mathrm{Kg} / \mathrm{cm}^{2}\right)[11]$.

\section{Friability (F).}

Friability of the tablet determined by using Roche friabilator which subjects tablets to the combined effect of abrasion and shock in a plastic chamber revolving at $25 \mathrm{rpm}$ and dropping a tablet at a height of 6 inches in each revolution. Pre-weighed 20 tablets were placed in the friabilator and were subjected to the 100 revolutions. The friability (F) is estimated by the given equation [12].

$$
\mathrm{F}=\left(\mathrm{W}_{1}-\mathrm{W}_{2}\right) / \mathrm{W}_{1}^{\star} 100
$$

Where, $\mathrm{W}_{1}$ :- Tablets weight before friability.

$\mathrm{W}_{2}$ :- Tablets weight after friability.

\section{Weight variation.}

According to Indian Pharmacopeia (IP), 2010 a weight variation test was done by weighing 20 tablets individually, calculating the average weight, and comparing the individual weights to the average. Based on the IP 2010 limit for weight variation in the case of the tablets weighing $\geq 250 \mathrm{mg}$ is $\pm 5 \%$.

\section{Deviation $\%=($ Average tablet weight - Individual tablet weight $)$} / Average tablet weight $* 100$

\section{Wetting time.}

A piece of tissue paper $(10 \mathrm{~mm})$ folded twice was placed in a culture dish $(\mathrm{d}=6 \mathrm{~cm})$ containing $6 \mathrm{ml}$ of simulated saliva (phosphate buffer $\mathrm{pH}$ 7.4). A tablet was carefully placed on the surface of tissue paper and the time required to reach the upper surface of the tablet was noted as the wetting time [13].

\section{Water absorption ratio.}

A test was done with the same procedure as that of wetting time. In this test, the initial weight of the tablet was noted before placing it on a Petri dish. After complete wetting, the wetted tablet was then weighed [13].

The water absorption ratio ' $\mathrm{R}$ ' was determined using the equation,

$$
\mathrm{R}=100 \times(\mathrm{Wa}-\mathrm{Wb}) / \mathrm{Wa}
$$

Where, $\mathrm{Wa}=$ Tablet weight after water absorption.

$\mathrm{Wb}=$ Tablet weight before water absorption.

\section{Dispersion time.}

The dispersion time was calculated via dipping two tablets in a glass contain $100 \mathrm{ml}$ of water. Three tablets from each formulation were randomly selected and dispersion time was measured $[14,15]$.

\section{In-vitro disintegration time.}

The test was carried out on 6 tablets using the apparatus specified in IP 2010. One tablet was kept in each tube of the basket and a plastic disc was located in each tube. The basket with the base surface made of a stainless-steel screen (mesh \# 10) was immerse in a water bath $37^{\circ} \mathrm{C} \pm 2{ }^{\circ} \mathrm{C}$ was used as a disintegration media and the time taken for complete disintegration of the tablet with no palatable mass remaining in the apparatus was measured in seconds [16]. 


\section{Uniformity of content.}

One tablet was powdered and added $50 \mathrm{ml}$ of $0.1 \mathrm{M}$ hydrochloric acid, heated on a water bath at $70^{\circ} \mathrm{C}$ for 15 minutes, cooled, diluted to $100 \mathrm{ml}$ with water, and filtered. To $20 \mathrm{ml}$ of this solution added $15 \mathrm{ml}$ of $1.25 \mathrm{M}$ sodium hydroxide and extracted with three quantities, each of $30 \mathrm{ml}$, of chloroform, dried each extracted with anhydrous sodium sulfate and filtered. Diluted the combined extracts to 100 $\mathrm{ml}$ with chloroform and mixed. Measure the absorbance of the resulting solution at the maximum at about 305 $\mathrm{nm}$. Calculated the contain Metoclopramide hydrochloride, taking 265 as the specific absorbance [17].

\section{Assay of tablets.}

20 tablets weighed and powdered into mortar pestle. Weigh accurately a quantity of the powder containing $10 \mathrm{mg}$ of anhydrous Metoclopramide hydrochloride, added $50 \mathrm{ml}$ of $0.1 \mathrm{M}$ hydrochloric acid, and heated on a water bath at 700 for 15 minutes, cooled, diluted to $100 \mathrm{ml}$ with water, and filtered. To $20 \mathrm{ml}$ of this solution, added $15 \mathrm{ml}$ of 1.25 $\mathrm{M}$ sodium hydroxide and extracted with three quantities, each of $30 \mathrm{ml}$, of chloroform, dried each extracted with anhydrous sodium sulfate and filtered. Diluted the combined extracts to $100 \mathrm{ml}$ with chloroform and mixed. Measure the absorbance of the resulting solution at the maximum at about $305 \mathrm{~nm}$ by using UV Visible Spectrophotometer, PG Instrument Limited, United Kingdom. Calculated the contain Metoclopramide hydrochloride, taking 265 as the specific absorbance [17].

\section{RESULTS}

\section{Drug-Excipient Compatibility Study}

All the drug-excipient stored vials were inspected physical state for a month. Physical state, color, and odor of drug-excipient mixture were compatible in both normal room temperature and accelerated temperature conditions. Since, all excipients were appropriate for formulation of Metoclopramide $\mathrm{HCl}$ oral disintegrating tablets.

Table 1 revealed the details of the components of the formulation of Metoclopramide hydrochloride ODT.

\section{Evaluation of pre-formulation parameter}

The results revealed that all formulation has good and fair flow properties. The angles of repose and compressibility index of all nine formulations were in the range of $30^{\circ}$ to $35^{\circ}$ and 18-23 respectively. MHF9 had the best angle of repose i.e., 30.11, and Compressibility index of 18 in comparison to other formulations. Thus, MHF9 shows the best flow property. The summary of the angle of repose, compressibility index, and Hausner's ratio is tabulated in Table 2 .

\section{Evaluation parameter of formulated tablets}

All the formulated tablets were subjected to general appearance and chemical evaluation. Entire formulated tablets with white color having flat face beveled edge round having standard bisect break line in one face and smooth face on another side. The average thickness and the average weight of the sample tablets from all formulation were found to be 3.03-3.07 $\mathrm{mm}$ and $237.32-263.10 \mathrm{mg}$, which was within the IP range as depicted in Table 3 .

The summary of diameter, hardness, friability, disintegration time, dispersion time, wetting time, water absorption ratio, content uniformity, and the assay is tabulated in Table 4 . The diameter of all the formulation was $10 \mathrm{~mm}$. The hardness of the made-up formulation was optimum. Friability test results show that the entire formulation was mechanically stable i.e. was within IP 2010 range $\leq 1 \%$ [17]. Among all the formulation MHF2 has the best friability. The disintegration and dispersion time of all the formulations was within the range i.e. within 3 minutes as per IP 2010. Among them, MHF9 shows the best disintegration time and dispersion time of $7 \mathrm{sec}$ and $18 \mathrm{sec}$ respectively in which $4.8 \%$ crospovidone was used. All the formulations were dispersed uniformly within the time and all the formulation was passed through $710 \mu \mathrm{m}$ as per IP except MHF1, MHF2, and MHF3. So these three (MHF1, MHF2, and MHF3) do not comply with IP 2010 [17]. Among all the formulations, MHF9 showed the best wetting time i.e. 28 seconds. The uniformity of content and drug assay of entire formulation was within the limit (90\% to $110 \%)$ as per IP 2010 [17]. Among all the formulation MHF9 shows the best uniformity of content and assay which was found to be $102.99 \%$ and $102.91 \%$ respectively.

\section{Comparative study of super disintegrants Disintegration time}

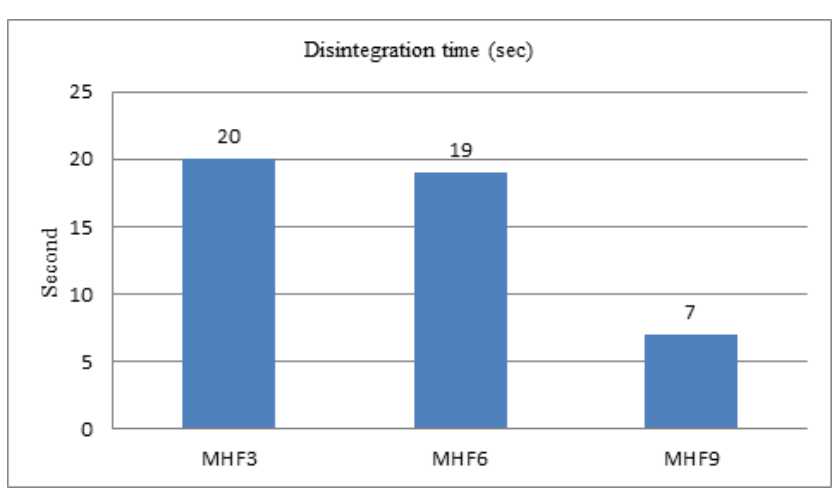

Fig 01: Bar diagram comparing disintegration time of various super disintegrants

Comparing three super disintegrants sodium starch glycolate, croscarmellose sodium, and crospovidone in varying concentration, we found that crospovidone concentration (4.8\%) show the best disintegration than other two super disintegrants. Among all the three formulation prepared by using sodium starch glycolate, MHF1 (concentration $2.8 \%$ ), MHF2 (concentration $4 \%$ ), and MHF3 (concentration 4.8 $\%)$; MHF3 showed comparatively better disintegration time 
Table 1: Formulation chart of Metoclopramide Hydrochloride ODT

\begin{tabular}{|c|c|c|c|c|c|c|c|c|c|c|}
\hline S.no. & Ingredients (mg/tablet) & MHF1 & MHF2 & MHF3 & MHF4 & MHF5 & MHF6 & MHF7 & MHF8 & MHF9 \\
\hline 1. & Metoclopramide $\mathrm{HCl}$ & 10.57 & 10.57 & 10.57 & 10.57 & 10.57 & 10.57 & 10.57 & 10.57 & 10.57 \\
\hline 2. & Sodium starch glycolate & 7 & 10 & 12 & - & - & - & - & - & - \\
\hline 3. & Crosscarmellose sodium & - & - & - & 7 & 10 & 12 & - & - & - \\
\hline 4. & Crospovidone & - & - & - & - & - & - & 7 & 10 & 12 \\
\hline 5. & $\begin{array}{l}\text { Microcrystalline cellulose } \mathrm{pH} \\
102\end{array}$ & 158.43 & 155.43 & 153.43 & 158.43 & 155.43 & 153.43 & 158.43 & 155.43 & 153.43 \\
\hline 6. & Sodium saccharin & 5 & 5 & 5 & 5 & 5 & 5 & 5 & 5 & 5 \\
\hline 7. & Magnesium stearate & 5 & 5 & 5 & 5 & 5 & 5 & 5 & 5 & 5 \\
\hline 8. & Mannitol & 50 & 50 & 50 & 50 & 50 & 50 & 50 & 50 & 50 \\
\hline 9. & Flavor (vanilla) & 4 & 4 & 4 & 4 & 4 & 4 & 4 & 4 & 4 \\
\hline 10. & Talc & 5 & 5 & 5 & 5 & 5 & 5 & 5 & 5 & 5 \\
\hline \multirow[t]{2}{*}{11.} & Aerosil & 5 & 5 & 5 & 5 & 5 & 5 & 5 & 5 & 5 \\
\hline & Total wt. (mg) & 250 & 250 & 250 & 250 & 250 & 250 & 250 & 250 & 250 \\
\hline
\end{tabular}

Table 2: Evaluation of pre-formulation parameter

\begin{tabular}{llll}
\hline Formulation & Angle of repose (In degree) & Compressibility index (\%) & Hausner's ratio \\
\hline MHF1 & $34.01 \pm 0.52$ & $22.22 \pm 0.13$ & $1.32 \pm 0.015$ \\
MHF2 & $34.21 \pm 0.50$ & $20.98 \pm 0.10$ & $1.30 \pm 0.014$ \\
MHF3 & $32.9 \pm 0.49$ & $21.73 \pm 0.11$ & $1.31 \pm 0.016$ \\
MHF4 & $34.0 \pm 0.51$ & $23.0 \pm 0.15$ & $1.31 \pm 0.013$ \\
MHF5 & $34.21 \pm 0.53$ & $19.0 \pm 0.12$ & $1.24 \pm 0.015$ \\
MHF6 & $34.22 \pm 0.52$ & $21.42 \pm 0.17$ & $1.27 \pm 0.019$ \\
MHF7 & $31.13 \pm 0.46$ & $20.83 \pm 0.15$ & $1.26 \pm 0.018$ \\
MHF8 & $31.79 \pm 0.47$ & $20.0 \pm 0.14$ & $1.25 \pm 0.015$ \\
MHF9 & $30.11 \pm 0.54$ & $18.0 \pm 0.19$ & $1.22 \pm 0.020$ \\
\hline
\end{tabular}

All data are expressed in mean $\pm \operatorname{SD}(n=3)$.

Table 3: Thethickness and weight variation of Metoclopramide $\mathrm{HCl}$

\begin{tabular}{|c|c|c|c|c|c|c|c|}
\hline \multirow{2}{*}{ Formulations } & \multicolumn{5}{|c|}{ Thickness (mm) } & \multirow{2}{*}{$\begin{array}{l}\text { Average } \\
\text { wt. (mg) }\end{array}$} & \multirow{2}{*}{ Dev. ${ }^{*}$} \\
\hline & Tablet 1 & Tablet 2 & Tablet 3 & Tablet 4 & Tablet 5 & & \\
\hline MHF1 & 3.01 & 3.00 & 3.013 & 3.02 & 3.06 & 249.83 & $237.37-262.32$ \\
\hline MHF2 & 3.09 & 3.011 & 3.08 & 3.00 & 3.012 & 249.58 & 237.101-262.059 \\
\hline MHF3 & 3.00 & 3.014 & 3.014 & 3.019 & 3.016 & 250.51 & $237.50-262.51$ \\
\hline MHF4 & 3.015 & 3.24 & 3.22 & 3.017 & 3.02 & 250.91 & $238.36-263.45$ \\
\hline MHF5 & 3.019 & 3.00 & 3.011 & 3.00 & 3.014 & 250.16 & $237.65-262.66$ \\
\hline MHF6 & 3.011 & 3.021 & 3.015 & 3.018 & 3.021 & 250.35 & $237.83-262.86$ \\
\hline MHF7 & 3.022 & 3.016 & 3.00 & 3.00 & 3.013 & 250.58 & $238.01-263.1$ \\
\hline MHF8 & 3.06 & 3.018 & 3.023 & 3.09 & 3.01 & 249.2 & $237.32-262.3$ \\
\hline MHF9 & 3.09 & 3.01 & 3.016 & 3.017 & 3.017 & 250.25 & $237.73-262.76$ \\
\hline
\end{tabular}

$\mathrm{Dev}^{*}$ : Deviation $( \pm 5)$ of average wt. as per IP 2010 
Table 4: Evaluation parameter of formulated tablets

\begin{tabular}{|c|c|c|c|c|c|c|c|c|c|}
\hline \multirow{2}{*}{ Evaluation parameters } & \multicolumn{9}{|c|}{ Designed formulations } \\
\hline & MHF1 & MHF2 & MHF3 & MHF4 & MHF5 & MHF6 & MHF7 & MHF8 & MHF9 \\
\hline $\begin{array}{l}\text { Diameter }(\mathrm{mm}) \text { Mean } \\
(\mathrm{n}=5)\end{array}$ & 10 & 10 & 10 & 10 & 10 & 10 & 10 & 10 & 10 \\
\hline Hardness $(\mathrm{kg} / \mathrm{cm} 2)$ & 2.58 & 2.66 & 2.06 & 2.40 & 2.33 & 2.50 & 2.83 & 2.56 & 2.68 \\
\hline Friability (\%) & 0.55 & 0.42 & 0.62 & 0.73 & 0.71 & 0.69 & 0.72 & 0.69 & 0.72 \\
\hline Disintegration time $(\mathrm{sec})^{*}$ & $30 \pm 0.31$ & $35 \pm 0.40$ & $20 \pm 0.30$ & $28 \pm 0.28$ & $24 \pm 0.29$ & $19 \pm 0.28$ & $15 \pm 0.26$ & $10 \pm 0.27$ & $7 \pm 0.25$ \\
\hline Dispersion time $(\mathrm{sec})^{\star}$ & $82 \pm 1.05$ & $71 \pm 1.06$ & $43 \pm 1.07$ & $56 \pm 1.05$ & $55 \pm 1.10$ & $40 \pm 1.06$ & $26 \pm 1.07$ & $24 \pm 1.05$ & $18 \pm 1.02$ \\
\hline Wetting time $(\mathrm{sec})^{*}$ & $36.33 \pm 1.20$ & $120 \pm 1.24$ & $68.6 \pm 1.31$ & $91.3 \pm 1.27$ & $78 \pm 1.31$ & $79 \pm 1.26$ & $31 \pm 1.28$ & $29.66 \pm 1.29$ & $28 \pm 1.26$ \\
\hline Water absorption ratio & 99.92 & 106.41 & 153.07 & 113.81 & 123.65 & 153.19 & 112.49 & 119.15 & 115.38 \\
\hline Uniformity of content (\%) & 91.2 & 91.43 & 97.67 & 95.49 & 99.24 & 97.25 & 95.93 & 102.33 & 102.99 \\
\hline Assay (\%) & 100.06 & 99.40 & 96.77 & 97.50 & 101.87 & 94.73 & 99.66 & 100.98 & 102.91 \\
\hline
\end{tabular}

${ }^{\star}$ Each value denotes the mean $\pm \mathrm{SD}(\mathrm{n}=3)$

compared to the other two concentrations. Among the three formulation prepared by using Croscarmellose sodium, MHF4 (concentration $2.8 \%$ ), MHF5 (concentration $4 \%$ ) and MHF6 (concentration $4.8 \%$ ); MHF6 showed better disintegration time. Among three formulation prepared by using crospovidone, MHF7 (concentration $2.8 \%$ ), MHF8 (concentration $4 \%$ ) and MHF9 (concentration $4.8 \%$ ); MHF9 showed comparatively better disintegration time. These results are in line with the previous study conducted by Satpute et al., SSG, CCS, and CP were in use as super disintegrants for Metoprolol orally disintegration tablets formulation. In this previous study by satpute et al., the crospovidone (6.6\%) containing formulation show a better disintegration time [18].

\section{Dispersion time}

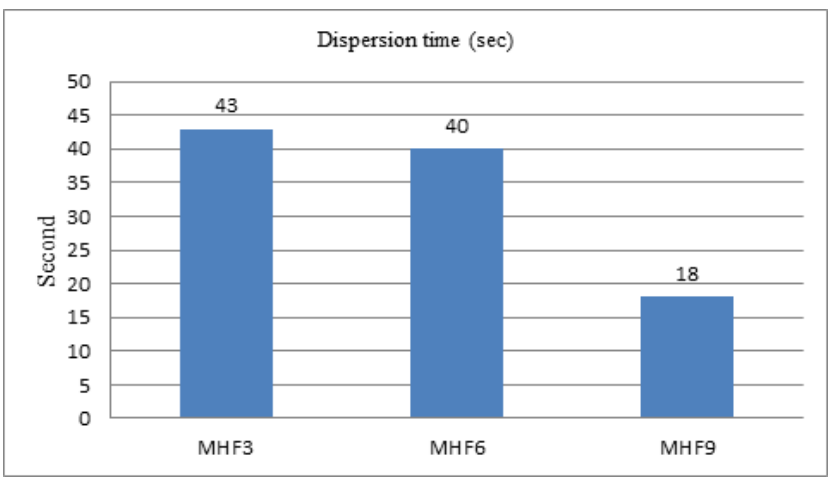

Fig 02: Bar diagram comparing the dispersion time of various super disintegrants

Comparing three super disintegrants sodium starch glycolate, croscarmellose sodium, and crospovidone in varying concentration, we found that crospovidone concentration (4.8\%) show the best dispersion time than other two super disintegrants. Among all the three formulation prepare by using sodium starch glycolate, MHF1 (concentration 2.8 $\%)$, MHF2 (concentration $4 \%$ ), and MHF3 (concentration
$4.8 \%$ ); MHF3 showed comparatively better dispersion time compare to the other two concentration. Among the three formulation prepared by using Croscarmellose sodium, MHF4 (concentration $2.8 \%$ ), MHF5 (concentration $4 \%$ ) and MHF6 (concentration $4.8 \%$ ); MHF6 showed better dispersion time. Among three formulation prepared by using crospovidone, MHF7 (concentration $2.8 \%$ ), MHF8 (concentration $4 \%$ ) and MHF9 (concentration $4.8 \%$ ) showed comparatively better dispersion time. These results are in agreement with the study conducted by Hussam et al., CP was found to be the best super disintegrant with a concentration of $40 \mathrm{mg} / \mathrm{tab}$ [19].

\section{DISCUSSION}

The present research was undertaken to formulate the ODTs of Metoclopramide hydrochloride through direct compression technique with various super disintegrant with various concentrations and keeping other excipients the same. Three different super disintegrants were used i.e. croscarmellose sodium, sodium starch glycolate, and crospovidone. The primary requirement for all the dosage forms is to disintegrate quickly. A total of nine formulations were prepared and evaluate the pre-formulation parameters like bulk density, tapped density, angle of repose, compressibility index, and Hausner's ratio. The formulated tablets meet the pharmacopeia requirements of the angle of repose, compressibility index, and uniformity of weight, friability, disintegration time, dispersion time, and uniformity of dispersion as per IP 2010. All the pre-formulation studies were found within prescribed limits and indicated well to fair free-flowing nature. Each drug-excipients mixture was found to be compatible for a month. Values for an angle of repose were found in the range of $30.11^{\circ}$ to $34.22^{\circ}$ showing that the blend of powder was free-flowing and can be used for direct compression. The value of compressibility index was found in the range of 23 to 22.22 , demonstrating that entire batches of tablet granules have good flow ability properties. Hausner's ratio was found to be in the range 
of 1.32 to 1.22 also indicates good flow properties. The breaking force of tablets was found to be in the range of 2.3 to $3.03 \mathrm{~kg} / \mathrm{cm}^{2}$. Friability was observed between 0.42 to $0.73 \%$. Thus the hardness and friability data indicate good mechanical resistance of tablets. The tablet thickness of all nine formulations varied from $2.98 \mathrm{~mm}$ to $3.041 \mathrm{~mm}$. The average weight of the tablet is $250 \mathrm{mg}$. According to IP 2010, the $\%$ deviation weight of $250 \mathrm{mg}$ or more tablets is $\pm 5 \%$, so the range is 237 to $263.45 \mathrm{mg}$. The sample tablets from all the formulations were within the range. In-vitro disintegration time for different batches ranges from 7 (MHF9) to 35 (MHF2) seconds. This was one test to be considered to select one best formulation from nine formulations. According to this test, MHF9 is the best formulation as it showed the lowest time for disintegration i.e. 7 sec., when the amount of super disintegrants crospovidone increases up to $4.8 \%$ per tablet, the disintegration time decrease. Wetting time is determined to get the idea of wetting lag time before disintegration and also found that as the wetting time decreased disintegration time also decreased. Wetting time is directly proportional to the Dispersion time, when the wetting time of tablets was deceased, increases the dispersion time of the tablets. The wetting time value of this test ranges from 28 (MHF9) to 120 (MHF2) sec. Dispersion time of all the formulations was within the range i.e. within $3 \mathrm{~min}$ as per IP (2010). Among them, MHF9 Shows the best dispersion time of $18 \mathrm{sec}$ in which $4.8 \%$ crospovidone was used. Dispersion time of all the formulations was complying with IP but in case of MHF1 and MHF2; dispersion time is longer than other formulations. Dispersion times of these two formulations (MHF1 and MHF2) is longer due to SSG which is nonporous in nature and are exaggerated via the presence of hydrophobic excipients and lubricating agents. Since crospovidone and croscarmellose sodium showed better dispersion as well as disintegrating time than SSG. This may be due to rapid capillary and swelling action. Thus these results indicate that these tablets would disintegrate almost instantaneously when they will come in contact with even a slight quantity of saliva in the mouth. The formulation (MHF9) having $4.8 \%$ of crospovidone showed the best results when compared to other formulations. In a previous study done by Mohanachandran, the disintegration time was reduced to $21 \mathrm{sec}$ on increasing the concentration of CP [20]. $\mathrm{CP}$ provides the best overall sensory experience as well as rapid disintegration and robustness [4]. Thus the liberating rate of Metoclopramide $\mathrm{HCl}$ was significantly enhanced by formulating ODT using $\mathrm{CP}$ as a super disintegrating agent. Its assay was obtained $102.91 \%$, disintegration, and dispersion time was obtained $7 \mathrm{sec}$ and $18 \mathrm{sec}$ respectively. Among all the formulations containing different concentrations of Croscarmellose sodium, Crospovidone, and Sodium starch glycolate; formulation MHF9 containing Crosspovidone of $4.8 \%$ shows better dispersion as well as disintegration time than Crosscarmellose and Sodium starch glycolate. This may be due to the rapid capillary and swelling action of Crosspovidone. Hence, these finding revealed that disintegration time can be minimize through using a wicking type of super disintegrating agent such as Crospovidone [18].

\section{CONCLUSION}

Oral disintegrating tablets of Metoclopramide hydrochloride can be successfully prepared by direct compression techniques using three super disintegrants i.e., sodium starch glycolate, crospovidone, and croscarmellose sodium. The ODTs prepared by using crospovidone $(4.8 \%)$ by direct compression is more efficient by the evaluation parameter (disintegration time, dispersion time, and wetting time) concerning other super disintegrants (SSG and CCS). In conclusion, the orally disintegrating tablets of Metoclopramide hydrochloride would be quite effective in emetic patients by providing rapid onset of action without the need for water during the administration. The overall rank order of disintegrating ability among disintegrants used was found to be $\mathrm{CP}>\mathrm{CCS}>\mathrm{SSG}$.

\section{ACKNOWLEDGEMENT}

The authors are thankful to Chemi-Drug Industries, Pvt. Ltd., Kathmandu, Nepal, for providing us active and others excipients and allowing for study drug-excipients interaction. Also, we would like to thank the Department of Pharmacy, Asian College for Advance Studies, Lalitpur for their supporting throughout the research.

\section{CONFLICT OF INTEREST: Nil.}

\section{REFERENCES}

1) Lakshmi A, Patel R, Kumar D. Formulation and evaluation of fast dissolving tablets of antiemetic drug metoclopramide. World J Pharm Pharm Sci. 2014;3:2080-2090.

2) Mahanthesh $M$, Nagaraja $T$, Lakshmi R, Vijaya $T$, Mallamma $T$. Formulation and evaluation of Metoclopramide mouth dissolving tablets. Journal of Pharma Innovation. 2012;12(3):22-32.

3) Mahore J, Wadhe K, Umekar M. Formulation and in-vitro evaluation of taste masked orodispersible tablet of metoclopramide hydrochloride. International Journal of PharmTech Research. 2010;2(3):1827-1835.

4) Gupta D, Agarwal D, Tyagi S, Sharma R, Gupta R, Sharma K. Natural \& synthetic superdisintegrants in FDT: a review. Int J Adv Res. 2013;1(6):576-583.

5) Gupta AK, Mittal A, Jha K. Fast dissolving tablet-A review. The pharma innovation. 2012;1(1).

6) El-Sayed YM, Niazy EM, Khidr SH. In vivo evaluation of sustainedrelease microspheres of metoclopramide hydrochloride in beagle dogs. International Journal of Pharmaceutics. 1995;123(1):113-118. Available from: https://dx.doi.org/10.1016/0378-5173(95)00054-m.

7) Reynolds JE. Martindale: the extra pharmacopoeia. London, UK. The Pharmaceutical Press. 1982.

8) Bozdag-Pehlivan S, Subasi B, Vural I, Unlu N, Capan Y. Evaluation of drug-excipient interaction in the formulation of celecoxib tablets. Acta Poloniae Pharmaceutica. 2011;68(3):423-433.

9) Pahwa R, Piplani M, Garg VK, Rao R, Lamba H. Formulation and evaluation of orally disintegrating tablets: comparison of natural and synthetic superdisintegrants. Der Pharmacia Lettre. 2011;3(2):407418.

10) Bhati S, Sethi V. Formulation and evaluation of fast dissolving tablets of metoclopramide hydrochloride using natural sweetening agent of stevia leaf powder. International Journal of Research and Development in Pharmacy \& Life Sciences. 2013;3(1):791-796. 
11) Gohel M, Patel M, Amin A, Agrawal R, Dave R, Bariya N. Formulation design and optimization of mouth dissolve tablets of nimesulide using vacuum drying technique. AAPS PharmSciTech. 2004;5(3):10-15. Available from: https://dx.doi.org/10.1208/pt050336.

12) USP U. The United States Pharmacopeia. Revision. 2019

13) Nagendrakumar D, and GKP. Design and evaluation of fast dissolving tablets of metoclopramide hydrochloride using synthetic and natural superdisintegrants . Unique J Pharm Biol Sci. 2014;2:16-24.

14) Khan $S$, Kataria P, Nakhat P, Yeole P. Taste masking of ondansetron hydrochloride by polymer carrier system and formulation of rapiddisintegrating tablets. AAPS PharmSciTech. 2007;8(2):E127-E133. Available from: https://dx.doi.org/10.1208/pt0802046.

15) Hiroyuki N, Kobayashi H, , Otoda K. Tablets quickly disintegrated in the oral cavity. European Patent (EP).1153616.

16) Thakare V, Jadhao U, Chaudhari K, Mahajan P. Development of metoclopramide hydrochloride orodispersible tablets using taste masking agent. Journal of Advanced Pharmacy Education \& Research. 2013;3(4):480-486.

17) The Government of India, Ministry of Health \& Family welfare The Indian Pharmacopeial commission, Ghaziabad, India. Pharmacopeia I;vol. II. 2010.

18) Satpute MM, Tour NS. Formulation and in vitro evaluation of fast dissolving tablets of metoprolol tartrate. Brazilian Journal of Pharmaceutical Sciences. 2013;49(4):783-792. Available from: https: //dx.doi.org/10.1590/s1984-82502013000400018.

19) Tizkam HH, Rassol A, Hussain AA. Preparation of a new dosage form of metoclopramide hydrochloride as orodispersible tablet. Iraqi Journal of Pharmaceutical Sciences. 2009;18(1):38-48.

20) Mohanachandran P, Sindhumol P, Kiran T. Superdisintegrants: an overview. International journal of pharmaceutical sciences review and research. 2011;6(1):105-109. 